\title{
Highly Absorbent Antibacterial Hemostatic Dressing for Healing Severe Hemorrhagic Wounds
}

\author{
Ting-Ting Li ${ }^{1}$, Ching-Wen Lou ${ }^{2,3}$, An-Pang Chen ${ }^{4}$, Mong-Chuan Lee ${ }^{3}$, Tsing-Fen Ho ${ }^{5}$, \\ Yueh-Sheng Chen ${ }^{6}$ and Jia-Horng Lin $1,2,4,7,8, *$ \\ 1 Innovation Platform of Intelligent and Energy-Saving Textiles, School of Textiles, \\ Tianjin Polytechnic University, Tianjin 300387, China; tingtingli@tjpu.edu.cn \\ 2 Department of Chemistry and Chemical Engineering, Minjiang University, Fuzhou 350108, China; \\ cwlou@ctust.edu.tw \\ 3 Graduate Institute of Biotechnology and Biomedical Engineering, Central Taiwan University of Science and \\ Technology, Taichung 40601, Taiwan; mclee@ctust.edu.tw \\ 4 Laboratory of Fiber Application and Manufacturing, Department of Fiber and Composite Materials, \\ Feng Chia University, Taichung 40724, Taiwan; duncannano@gmail.com \\ 5 Department of Medical Laboratory Science and Biotechnology, Central Taiwan University of Science and \\ Technology, Taichung 40601, Taiwan; tfho@ctust.edu.tw \\ 6 Department of Biomedical Imaging and Radiological Science, China Medical University, Taichung 40402, \\ Taiwan; yuehsc@mail.cmu.edu.tw \\ 7 School of Chinese Medicine, China Medical University, Taichung 40402, Taiwan \\ 8 Department of Fashion Design, Asia University, Taichung 41354, Taiwan \\ * Correspondence: jhlin@fcu.edu.tw; Tel.: +886-4-2451-7250 (ext. 3405); Fax: +886-4-2451-0871
}

Academic Editor: Carsten Werner

Received: 7 June 2016; Accepted: 9 September 2016; Published: 21 September 2016

\begin{abstract}
To accelerate healing of severe hemorrhagic wounds, a novel highly absorbent hemostatic dressing composed of a Tencel ${ }^{\circledR} /$ absorbent-cotton/polylactic acid nonwoven base and chitosan/nanosilver antibacterial agent was fabricated by using a nonwoven processing technique and a freeze-drying technique. This study is the first to investigate the wicking and water-absorbing properties of a nonwoven base by measuring the vertical wicking height and water absorption ratio. Moreover, blood agglutination and hemostatic second tests were conducted to evaluate the hemostatic performance of the resultant wound dressing. The blending ratio of fibers, areal weight, punching density, and fiber orientation, all significantly influenced the vertical moisture wicking property. However, only the first two parameters markedly affected the water absorption ratio. After the nonwoven base absorbed blood, scanning electron microscope (SEM) observation showed that erythrocytes were trapped between the fibrin/clot network and nonwoven fibers when coagulation pathways were activated. Prothrombin time (PT) and activated partial thromboplastin time (APTT) blood agglutination of the resultant dressing decreased to 14.34 and $50.94 \mathrm{~s}$, respectively. In the femoral artery of the rate bleeding model, hemostatic time was saved by $87.2 \%$ compared with that of cotton cloth. Therefore, the resultant antibacterial wound dressing demonstrated greater water and blood absorption, as well as hemostatic performance, than the commercially available cotton cloth, especially for healing severe hemorrhagic wounds.
\end{abstract}

Keywords: nonwoven; fiber technology; nanosilver; hemostatic; wound dressing

\section{Introduction}

Personalized medicine is increasingly becoming mainstream with the aging society and low birth rate for humans, with particular attention given to perfect medical care. However, some circumstances such as traffic accidents, wartime firearms, typhoons, earthquakes, and tsunamis occasionally occur by 
surprise. These disasters may result in massive bleeding, which can trigger coma, shock, and even death for injured humans. During surgical operation, reducing the bleeding time and shortening the operation duration can significantly influence a patient's prognosis.

Wound dressing composed of collagen, chitosan, and sodium alginate [1-3] has extensive applications. Arafat et al. and Tronci et al., conducted many related studies on collagen and collagen wound dressing; in which they demonstrated that these dressings can achieve a certain mechanical strength, high swelling ratio, and triple helical features [4-6].

Blood comprises a large amount of water. Thus, hemostatic materials should be highly absorbent. As a cellulose fiber, Tencel ${ }^{\circledR}$ fiber contains a high proportion of swelling fibril bundles and presents moisture wicking properties [7]. The fiber structure and water-absorbing degree can determine the good skin affinity of Tencel ${ }^{\circledR}$ fiber. Moreover, this fiber demonstrates excellent moisture management capacity and absorbs water molecules into fiber molecules; thus, no excessive water remains on the superficial skin, and bacteria cannot grow, avoiding discomfort in people [8]. Polylactic acid (PLA) fiber is a biodegradable material with excellent biocompatibility; therefore, PLA fiber is widely used in drug controlled release, tissue engineering, and wound dressing. PLA fiber contains numerous carboxylate groups and presents a relatively hydrophobic character and brittle strength [9]. Absorbent cotton (AC) demonstrates excellent moisture-absorbing and water-retaining properties, and absorbed molecules can be successfully trapped among AC fibers without producing gravity water. However, fine fibers are prone to remain in the wounds even after removal [10]. Perfect wound dressing should exhibit (i) moisture-retaining properties; (ii) avoidance of secondary infection; (iii) blood and interstitial fluid absorption; (iv) excellent coverage and tear resistance; (v) good biocompatibility; and (vi) rapid healing [11-14]. Therefore, the blending of these fibers aims to provide appropriate strength, good biocompatibility, good moisture-retaining properties, and rapid blood absorption for resultant nonwoven dressings. Furthermore, such blending leads to quick hemostasis and creates a fast-healing moist environment for wound prognosis.

For healing severe hemorrhagic wounds, conventional hemostatic methods include digital pressure hemostasis, pressure dressing hemostasis, and tourniquet hemostasis. In particular, pressure dressing hemostasis results in successful hemostasis but it easily triggers complications if an inexperienced person performs the operation. Therefore, as a simple hemostatic method, a novel multi-component and porous nonwoven base composited with chitosan and silver nanoparticles can be directly pressed on the severe hemorrhagic spot to induce hemostasis.

During healing, microbial infection leads to inflammation [15]. Therefore, the antibacterial property becomes a required alternative for wound dressing. Chitosan, as a biodegradable, nontoxic, complex carbohydrate derivative of chitin demonstrates mucoadhesive activity and it can be considered an ideal candidate as a hemostatic agent [16]. This compound carries positive ions in acidic condition because of the amido group and combines with electronegative bacterial cells; the osmotic pressure between inside and outside of bacterial cells is then altered, resulting in antibacterial property. Moreover, chitosan offers excellent wound-healing potential [17], but such potential is limited to minor hemorrhages and insufficient to assess the potential efficacy of severe bleeding.

Nanosilver particles were reported to exert more significant antibacterial effects; therefore, the synthesis, characterization, and antibacterial activities of Ag nanoparticles in various approaches have become major topics for research [18-34]. Among these processes, the conventional synthesis of nanosilver particles uses large amounts of harmful solvents and reagents, such as hydrazine $\left(\mathrm{N}_{2} \mathrm{H}_{4}\right)$, sodium borohydride $\left(\mathrm{NaBH}_{4}\right)$, sodium hypophosphite $\left(\mathrm{NaH}_{2} \mathrm{PO}_{2}\right)$, and formaldehyde $(\mathrm{HCHO})$. Based on a green sustainable chemistry concept that aims to reduce the amounts of raw materials harmful to the human body and environment, as well as decrease the usage of catalysts and solvents and the generation of unnecessary chemical derivatives and their associated wastes, a novel green synthesis method was proposed to synthesize $\mathrm{Ag}$ nanoparticles in our laboratory by using chitosan and silver nitrate solution. The chitosan-encapsulated Ag nanoparticles were confirmed to be effective antibacterial agents against Escherichia coli and Staphylococcus aureus [35,36]. 
When fabricating a highly absorbent wound dressing, a highly absorbent structure and excellent blood-retaining property are essential. Although PLA fibers are relatively hydrophobic polymers that limit water uptake, these fibers can provide a supporting efficiency for nonwoven structures and absorb large amounts of blood in the nonwoven base. The blood is then held in the structure to prevent the blood from entering into the nonwoven base, thereby avoiding the production of gravity water and ejection of the blood. Consequently, a multi-component nonwoven structure containing Tencel ${ }^{\circledR}$ fibers, highly absorbent cotton, and PLA fibers was designed as a wound dressing base. Moreover, antibacterial chitosan-encapsulated Ag nanoparticles were doped into the nonwoven base. This study focused on the nonwoven composition and process parameters influencing the blood absorption-related properties, wicking and water-absorbing capabilities, and hemostatic performance in severe hemorrhage of rat femoral artery.

\section{Experimental Section}

\subsection{Materials and Methods}

In this experiment, $1.7 \mathrm{D}$ Tencel ${ }^{\circledR}$ fiber (Taiwan Web-Pro Co., Ltd., Kaohsiung, Taiwan), 1.6 D PLA fiber (Far Eastern New Century Corporation, Taipei, Taiwan), and 1.53 D absorbent-cotton (AC) fiber (Asiatic Fiber Corporation, Taipei, Taiwan) were fabricated into a Tencel ${ }^{\circledR} /$ AC $/$ PLA (TCP) nonwoven structure via processes including opening, blending, carding, lapping, and needle punching. The ratios of Tencel ${ }^{\circledR}$ fiber and PLA fiber in the nonwoven base were set as 40:40, 50:30, 60:20, 70:10, and 80:0 wt \%/wt \%, and the AC fiber was set as $20 \mathrm{wt} \%$. The punching density was set as 50, 75, and 100 punches $/ \mathrm{cm}^{2}$, and the areal weight was set as 100,150 , and $200 \mathrm{~g} / \mathrm{m}^{2}$. The effects of processing parameters on the vertical wicking height and water absorption ratio of TCP composite nonwoven structures were investigated. Blood absorption of nonwoven structures was also compared. The name codes of fabricated samples used for blood absorption are displayed in Table 1.

Table 1. Name codes of Tencel ${ }^{\circledR} /$ Absorbent-Cotton/PLA (TCP) composite nonwoven used for blood absorption.

\begin{tabular}{ccccccc}
\hline $\begin{array}{c}\text { Composite } \\
\text { Nonwoven }\end{array}$ & Tencel $^{\circledR}(\mathbf{w t} \mathbf{\%})$ & AC (wt \%) & PLA (wt \%) & $\begin{array}{c}\text { Punching } \\
\text { Density } \\
\left(\mathbf{P u n c h e s}_{\mathbf{c m}} \mathbf{)}\right)\end{array}$ & $\begin{array}{c}\text { Areal Weight } \\
\left(\mathbf{g} / \mathbf{m}^{\mathbf{2}}\right)\end{array}$ & $\begin{array}{c}\text { Thickness } \\
\mathbf{( m m )}\end{array}$ \\
\hline 40TCP & 40 & 20 & 40 & 100 & 100 & 0.85 \\
50TCP & 50 & 20 & 30 & 100 & 100 & 0.85 \\
60TCP & 60 & 20 & 20 & 100 & 100 & 0.85 \\
$70 \mathrm{TCP}$ & 70 & 20 & 10 & 100 & 100 & 0.85 \\
80TCP & 80 & 20 & 0 & 100 & 100 & 0.85 \\
\hline
\end{tabular}

About $80 \%$ of chitosan powder (Global Biological Technology Co., Ltd., Tainan, Taiwan) was dissolved in acetic acid by stirring at $25 \pm 2{ }^{\circ} \mathrm{C}$. Pure-grade silver nitrate solution (purchased from Union Chemical Works Ltd., Hsinchu, Taiwan) was then blended with the aforementioned chitosan solution to create a chitosan/nanosilver antibacterial agent. The green synthesis of the antibacterial agent was performed as described in our previous study [35]. The antibacterial agent was coated on the TCP nonwoven by free-drying, forming the resultant wound dressing. As a result, nanosilver was successfully covered on the surface of fibers (Figure 1). 


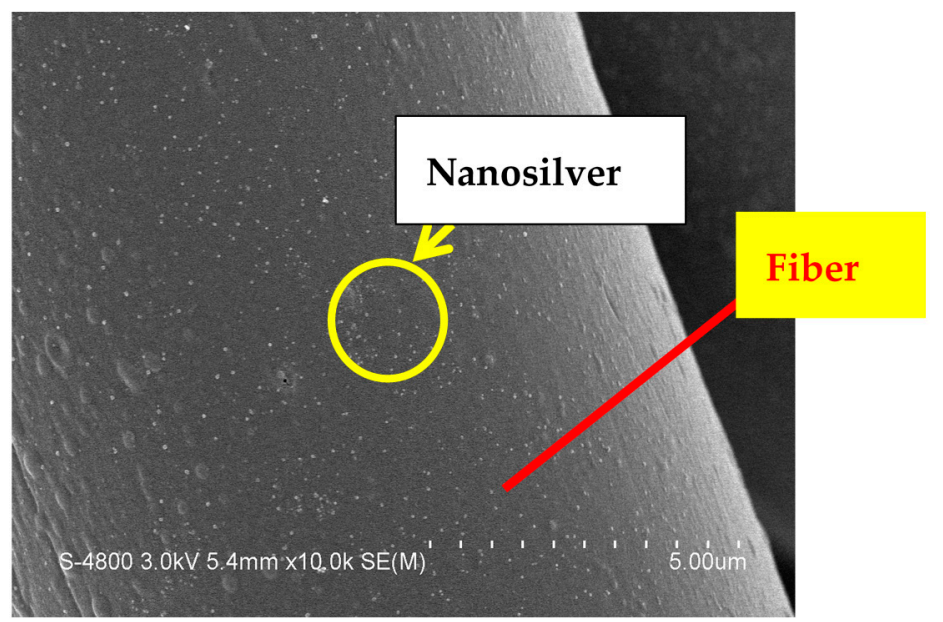

Figure 1. Scaning electron microscopy (SEM) observation of nanosilver-doped nonwoven fibers.

\subsection{Measurements}

\subsubsection{Vertical Wicking Height}

Five pieces of nonwovens along the cross machine direction (CD) and machine direction (MD) were cut into $200 \mathrm{~mm}$ (length) $\times 25 \mathrm{~mm}$ (width) in accordance with the standard of CNS 5611 . Each piece was vertically fastened on a horizontal clamper placed on top of a water tank. After soaking each piece in water for $10 \mathrm{~min}$, the vertical wicking height of each piece with different fiber blendings was determined.

\subsubsection{Water and Blood Absorption}

Each group of TCP nonwovens was cut into $50 \mathrm{~mm} \times 50 \mathrm{~mm}$ pieces. The weight of each piece was recorded as $W_{0}$. Each piece was then placed into a $250 \mathrm{~mL}$ beaker containing $80 \mathrm{~mL}$ of water and blood. Fresh and healthy whole blood was acquired from volunteers. After soaking the pieces in water and blood for $5 \mathrm{~min}$, each piece was weighed as $W_{\text {wet }}$. The water absorption ratio $(W)$ was calculated as follows:

$$
W=\left(W_{\text {wet }}-W_{0}\right) / W_{0}
$$

\subsubsection{Mechanical Property}

The tensile strength along the MD and CD of TCP nonwovens was tested in accordance with the standard of ASTM D5035-11. The Instron 5566 universal testing machine (Instron, Norwood, MA, USA) was used to measure the rectangular specimens. The crosshead speed was $300 \mathrm{~mm} / \mathrm{min}$. The tensile specimen measured $180 \mathrm{~mm}$ long and $25.4 \mathrm{~mm}$ wide.

Burst strength of TCP nonwovens was determined using Instron 5566 Tester (Instron, Norwood, MA, USA) in accordance with the standard of ASTM D1883. The semicircular-ended head ( $25 \mathrm{~mm}$ in diameter) attached to a $10 \mathrm{kN}$ load cell was driven onto the nonwovens at a speed of $100 \mathrm{~mm} / \mathrm{min}$.

\subsubsection{PT and APTT Experiments}

The blood test in this work was approved by the Institutional Animal Care and Use Committee (IACUC) with Approval No. 100-CTUST-22 and a protocol period going from 1 June 2012 to 5 May 2015. Prothrombin time (PT) and activated partial thromboplastin time (APTT) were measured to determine the effect of wound dressing on blood-clotting time. The PT test was performed on heparinized plasma, and the PT reagent comprised tissue factor, $\mathrm{CaCl}_{2}$, and phospholipid. The APTT test was performed by adding APTT reagent into heparinized plasma. The APTT reagent was composed of plasma activator, 
phospholipid, and $\mathrm{CaCl}_{2}$. The PT agent (APTT reagent) and wound dressing sample were added to plasma in the test tube, and PT (APTT) was tested at $37^{\circ} \mathrm{C}$ simultaneously.

\subsubsection{Animal Experiment}

Femoral artery bleeding of Wistar rats (purchased from BioLASCO Taiwan Co., Ltd., Taipei, Taiwan) was performed to evaluate hemostasis. A hemostatic wound dressing was then pressed on the bleeding site lightly for $2 \mathrm{~s}$ to absorb excessive blood voluntarily until hemostasis. The hemostasis time was expressed as the time between artery excision and bleeding stop.

\subsubsection{Statistical Analysis}

Statistical analysis of vertical wicking and water absorption, as well as hemostatic performance, was performed using one-way ANOVA with SPSS software (IBM, Chicago, IL, USA). Differences were considered statistically significant at ${ }^{*} p<0.05$ and ${ }^{* *} p<0.01$.

\section{Results and Discussion}

\subsection{Wicking and Water Absorption of Nonwoven Wound Dressing}

Figure 2 shows the vertical wicking and water absorption properties of TCP nonwovens with different Tencel ${ }^{\circledR}$ fiber contents. The PLA fiber, which was composed of a thermoplastic aliphatic polyester polymerized by lactide and lactic acid, demonstrated weak water absorption. This finding was ascribed to the byproducts formed in the carboxyl polymerization reaction, which did not occur in hydrophilic groups. In addition, given that PLA fibers exhibit high crystallinity, water molecules could not easily enter into the amorphous region. As a result, the Tencel ${ }^{\circledR}$ fiber contents significantly affected the vertical wicking weight of water molecules. Figure 2a shows that the vertical wicking height increased with the blending ratio of Tencel ${ }^{\circledR}$ fibers, because a higher number of molecular chains of Tencel ${ }^{\circledR}$ fibers contained more hydrophilic groups (e.g., $\mathrm{OH}$ groups), which could easily produce chemical-bonded water. This finding explained the vertical wicking height tendency of TCP nonwovens, similar to the water absorption illustrated in Figure $2 b$, in which the water absorption ratio steadily increased with the Tencel ${ }^{\circledR}$ fiber content. Figure 2a shows that $\mathrm{CD}$ displayed significantly higher wicking height than MD because the nonwoven base along $\mathrm{CD}$ contained a higher fiber content and more water molecules, capillaries, and channels [37]. About $80 \mathrm{wt} \%$ Tencel ${ }^{\circledR}$ fibers in nonwovens revealed very significantly higher vertical wicking height $(* * * 0.01)$ and significant water absorption ratio $\left({ }^{*} p<0.05\right)$ than $40 \mathrm{wt} \%$ Tencel ${ }^{\circledR}$ fibers in nonwovens.
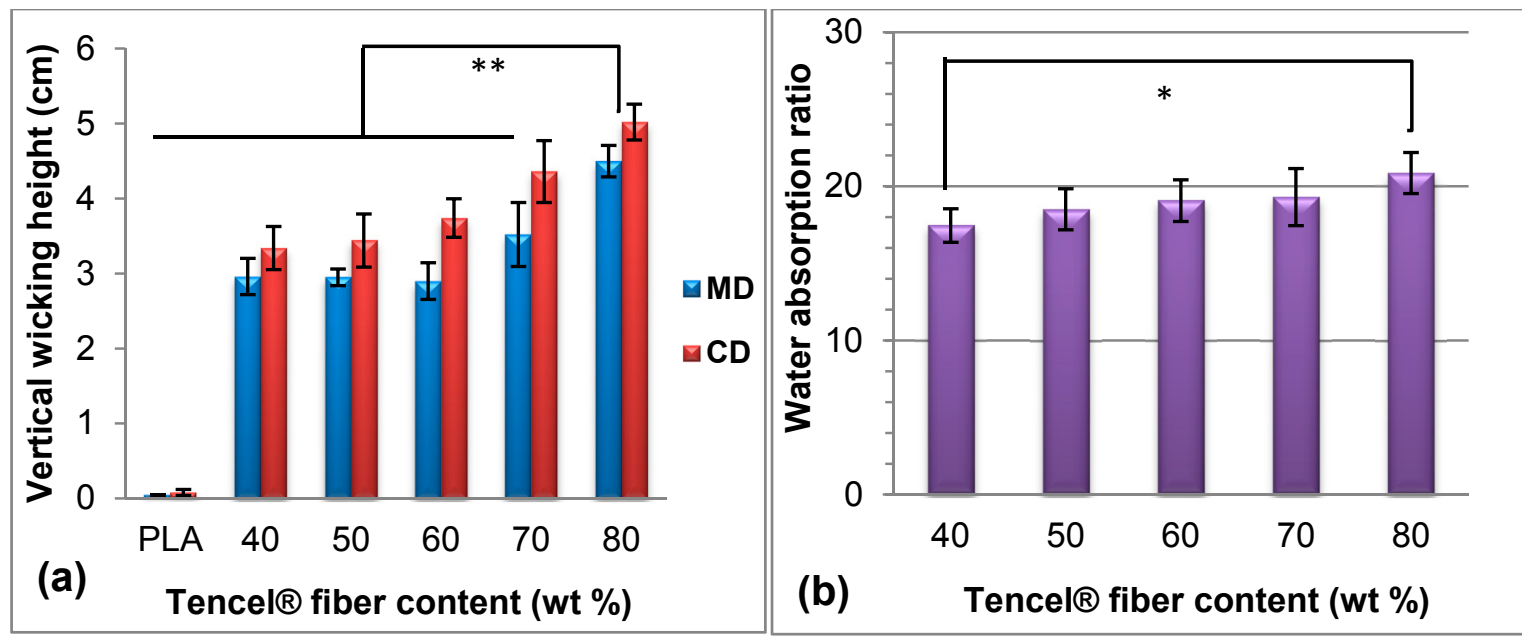

Figure 2. (a) Vertical wicking height and (b) water absorption of Tencel ${ }^{\circledR} /$ Absorbent-Cotton/PLA (TCP) nonwovens with various fiber blendings. ${ }^{* *} p<0.01{ }^{*} p<0.05$. 
Figure 3 shows the effect of punching density on vertical wicking height and water absorption ratio. In particular, the Tencel ${ }^{\circledR}$ fiber content was $40 \mathrm{wt} \%$, and the areal weight was $100 \mathrm{~g} / \mathrm{m}^{2}$. Figure 3a shows that the vertical wicking height increased with punching density from 50 punches $/ \mathrm{cm}^{2}$ to 100 punches $/ \mathrm{cm}^{2}$ because the contacting area between adjacent fibers increased with punching density. Circuitous water-absorbing channels also increased in number. This finding agreed well with the results of Çil et al., who reported that compact fabrics exhibit enhanced vertical wicking properties because of the good capillarity effect [38]. However, Figure 3b shows that the punching density was insignificantly correlated with the water absorption ratio. This finding demonstrated that fiber entanglements and nonwoven thickness reached a saturation state at 50-100 punches $/ \mathrm{cm}^{2}$ and could not promote moisture holding capacity among porous structures after thickness compression $[39,40]$.

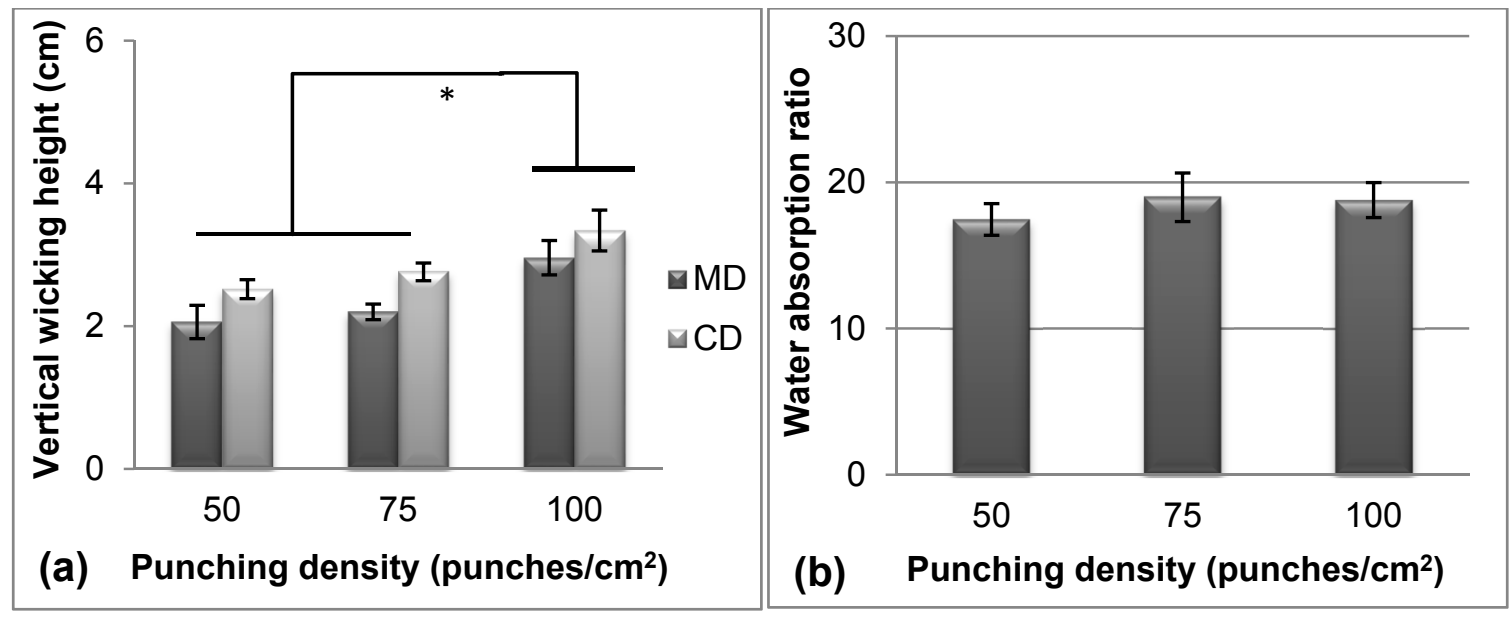

Figure 3. (a) Vertical wicking height and (b) water absorption of TCP nonwovens with various punching densities. ${ }^{*} p<0.05$.

Figure 4 shows the vertical wicking height and water absorption ratio of nonwovens with various areal weights, which significantly influenced the wicking and water-absorbing properties. As shown in Figure $4 \mathrm{a}$, the vertical wicking height steadily improved with the areal weight of the nonwoven. The nonwoven exhibited a porous structure, and liquid penetrated through the pores at extra pressure and capillary effect. With increasing areal weight of the nonwoven, the fiber content per unit volume increased, which led to frequent water diffusion and strong capillarity in each direction. A rapid diffusion rate and improved wicking property were both achieved when water diffused merely along the surface, as indicated by Duru et al. and Laughlin et al. [41,42]. Figure $4 \mathrm{~b}$ shows that the water absorption ratio decreased progressively as the areal weight increased from $100 \mathrm{~g} / \mathrm{m}^{2}$ to $200 \mathrm{~g} / \mathrm{m}^{2}$. The nonwoven exhibited a porous structure, and its fiber swelled after water absorption. However, a high areal weight of nonwoven indicated a high fiber content, and high additional compression from contacts of water molecules generated gravity water in a given space, so the water molecules presented difficulty in holding in the porous structure.

The different trends and significance of the vertical wicking height and water absorption ratio with the Tencel ${ }^{\circledR}$ content, punching density, and areal weight (Figures 3 and 4) were attributed to different mechanisms. The vertical wicking height was attributed to the water diffusion rate, and water absorption resulted from porosity and structure. Therefore, CD nonwoven demonstrated high fiber content and rapid diffusion rate, which resulted in high vertical wicking height, as displayed in Figures 2a, 3a and 4a. When the nonwoven contained $80 \mathrm{wt} \%$ Tencel ${ }^{\circledR}$ fibers, a weight of $100 \mathrm{~g} / \mathrm{m}^{2}$, and a punching density of 100 punches $/ \mathrm{cm}^{2}$, the vertical wicking height and water absorption ratio along CD reached $5.0 \mathrm{~cm}$ and 20.9 times, respectively. 

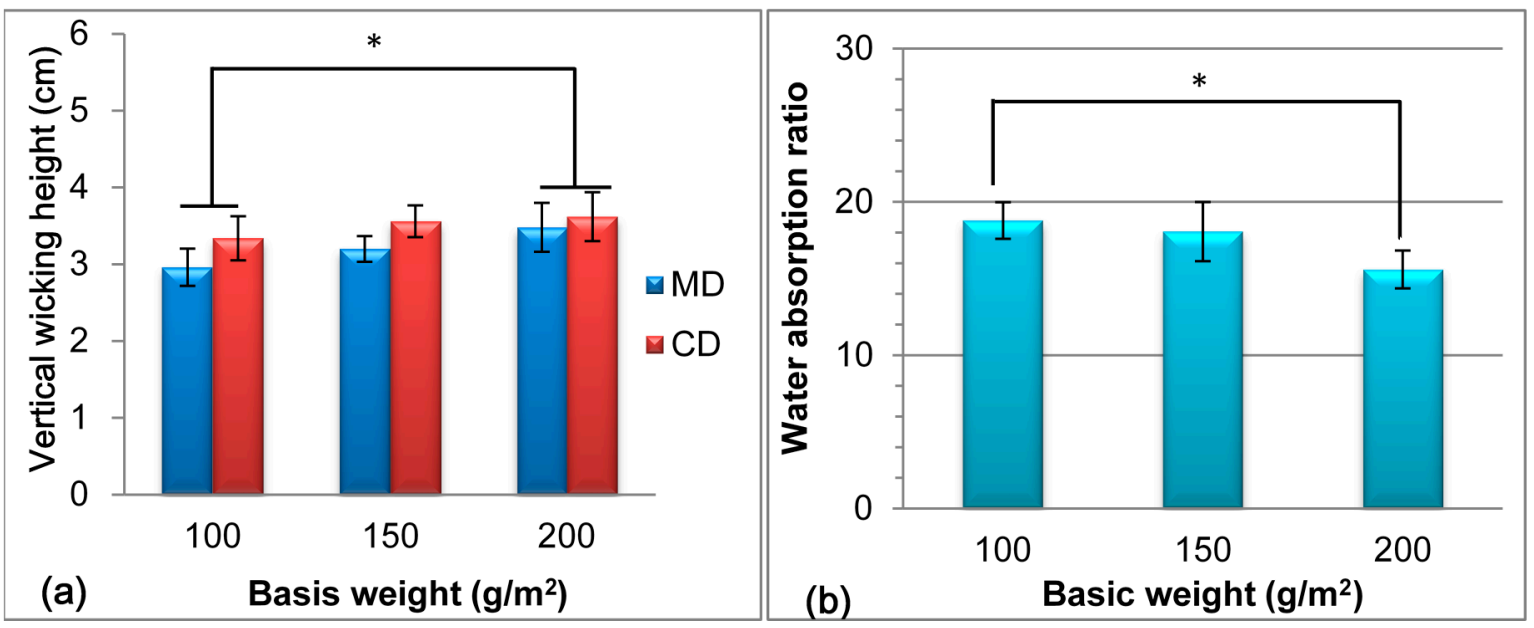

Figure 4. (a) Vertical wicking height and (b) water absorption of TCP nonwovens with various basal weights. ${ }^{*} p<0.05$.

\subsection{Mechanical Properties of Nonwoven Wound Dressings}

When absorbing a large amount of interstitial fluid, the fiber structure becomes loose and has a relatively low mechanical property, which brings inconvenience to medical workers. Moreover, the burst property can simulate the buckling load of wound dressing when applied on wrist, elbow, knee, and heel wounds. Therefore, fiber blendings that influence the mechanical properties are important to support the application of wound dressing. Figure 5 shows the mechanical properties of nonwoven wound dressings with different Tence ${ }^{\circledR}$ fiber amounts. In Figure 5a, the maximum breaking strength was enhanced when the Tencel ${ }^{\circledR}$ fiber content increased. When Tencel ${ }^{\circledR}$ fiber increased to $60 \mathrm{wt} \%$, the improvement for tensile strength revealed very significant $(* * p<0.01)$. This finding demonstrated that Tencel ${ }^{\circledR}$ fiber addition could make up the strength of the whole nonwoven dressing compared with pure PLA nonwoven, because the Tencel ${ }^{\circledR}$ fiber presented a tenacity of $3.2 \mathrm{~g} /$ denier higher than that of the PLA fibers [43]. Additionally, the tensile strength $(Y)$ displayed a highly linear correlation with the Tencel ${ }^{\circledR}$ fiber content $(x)$, as expressed in Equation (2).
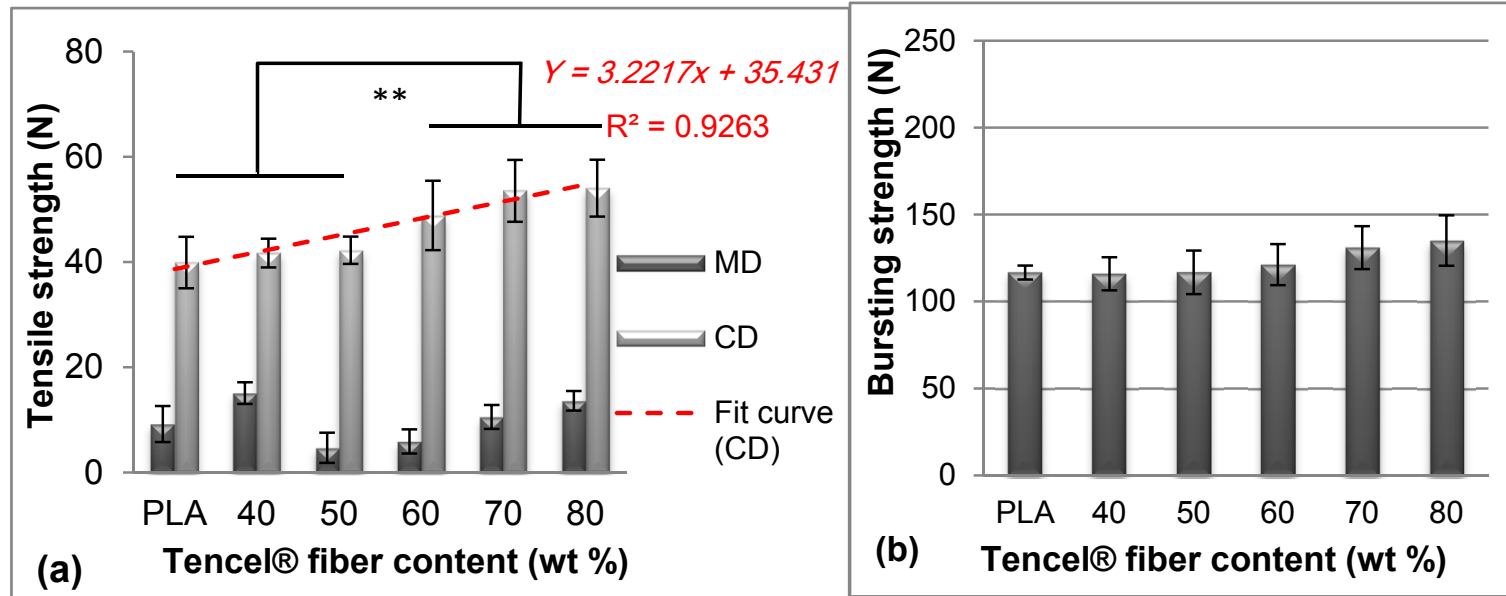

Figure 5. (a) Tensile strength and (b) burst strength of TCP nonwovens with various Tencel ${ }^{\circledR}$ fiber contents, punching density of 100 punches $/ \mathrm{cm}^{2}$, and areal weight of $100 \mathrm{~g} / \mathrm{m}^{2} .{ }^{* *} p<0.01$. 
When the Tencel ${ }^{\circledR}$ addition increased to $60 \%$, its improvement to tensile strength became very significant. However, the burst strength was insignificantly related to the Tencel ${ }^{\circledR}$ fiber content, as shown in Figure 5b. At the same areal weight, the fiber web in the thickness direction exhibited a relatively higher fiber volume density, even with different Tencel ${ }^{\circledR}$ fibers, and the compactness and entanglement interactively affected tensile load shared by the individual fibers [44]. Therefore, the burst strength did not significantly increase with the Tencel ${ }^{\circledR}$ fiber content, in contrast to the tensile strength results in Figure 5a. In conclusion, the nonwoven dressing base presented a tensile stress of 1.9-2.5 MPa and burst strength of 116-135 N, which could reach the mechanical levels of the wound dressing application.

\subsection{Blood Absorption of Nonwoven Wound Dressing}

Figure 6 shows that blood absorption with increasing Tencel ${ }^{\circledR}$ fiber content was similar to water absorption because blood consists of $55 \%$ plasma, which contains $92 \%$ water. Cotton cloth absorbed 4.5 times water and 3.6 times blood compared with its dry weight. Comparatively, water and blood absorptions reached 21.1 and 19.3 times for 80 TCP and 19.7 and 18.6 times for 60 TCP. Therefore, water and blood absorptions of TCP nonwoven were four to five times that of cotton cloth. The improvement in water and blood absorptions compared with cotton cloth was very significant $\left({ }^{* *} p<0.01\right)$, indicating the superior blood absorption capacity for the TCP nonwoven base. The blood absorption efficiency of the composite nonwoven reached $38 \mathrm{~g} / \mathrm{m}^{2}$, which was equivalent to that of various fabric dressings, ranging from $20 \mathrm{~g} / \mathrm{m}^{2}$ to $42 \mathrm{~g} / \mathrm{m}^{2}$, as reported by Terrill et al. [45].

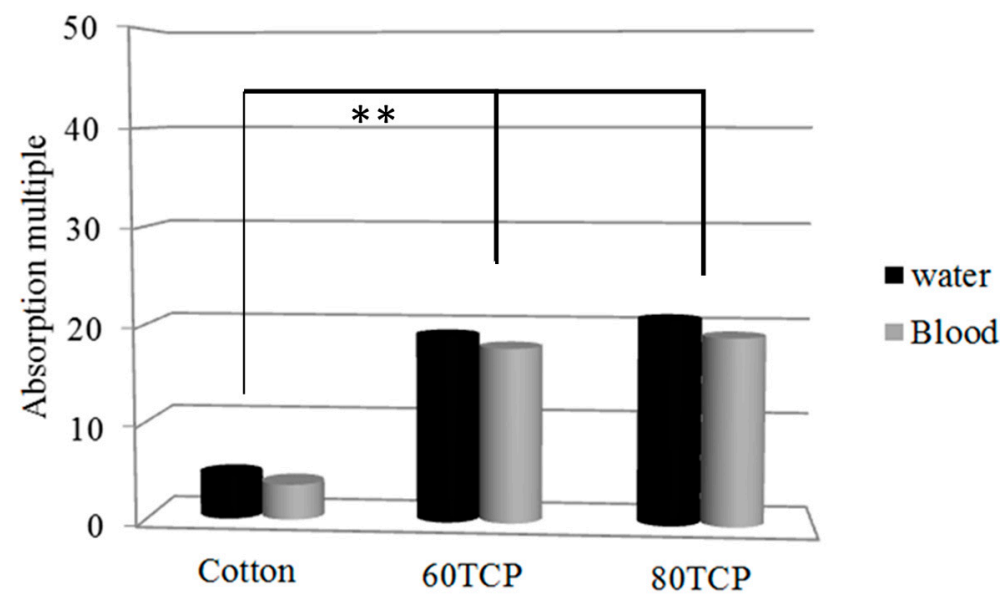

Figure 6. Water and blood absorptions of cotton cloth and TCP nonwovens with $60 \mathrm{wt} \%$ and $80 \mathrm{wt} \%$ Tencel ${ }^{\circledR}$ fibers. ${ }^{* *} p<0.01$.

Figure 7 shows the observations of cotton cloth and TCP nonwoven after blood absorption. A significant difference was found in blood absorption for cotton cloth and TCP nonwoven, upon comparing Figure 7a,b. Blood was absorbed only in fibers for cotton cloth, but it filled between the interspace of nonwoven fibers besides the fibrous part. This finding suggested the superior blood and water absorption for the TCP nonwoven base. Figure $7 \mathrm{c}, \mathrm{d}$ show that numerous erythrocytes (with diameters of 4-6 $\mu \mathrm{m}$ ) aggregated between fibers, and the coagulation reaction still occurred and formed clots. Although erythrocytes were in contact with nonwoven fibers, they were still trapped between the fibrin network and attached to the surface of nonwoven fibers when coagulation pathways were activated, which is explained by the cellular morphology of fibrin around the erythrocytes [46]. Therefore, the nonwoven fibers used in this study could not influence the coagulation mechanism but may be applied for future resultant hemostatic wound dressing. 


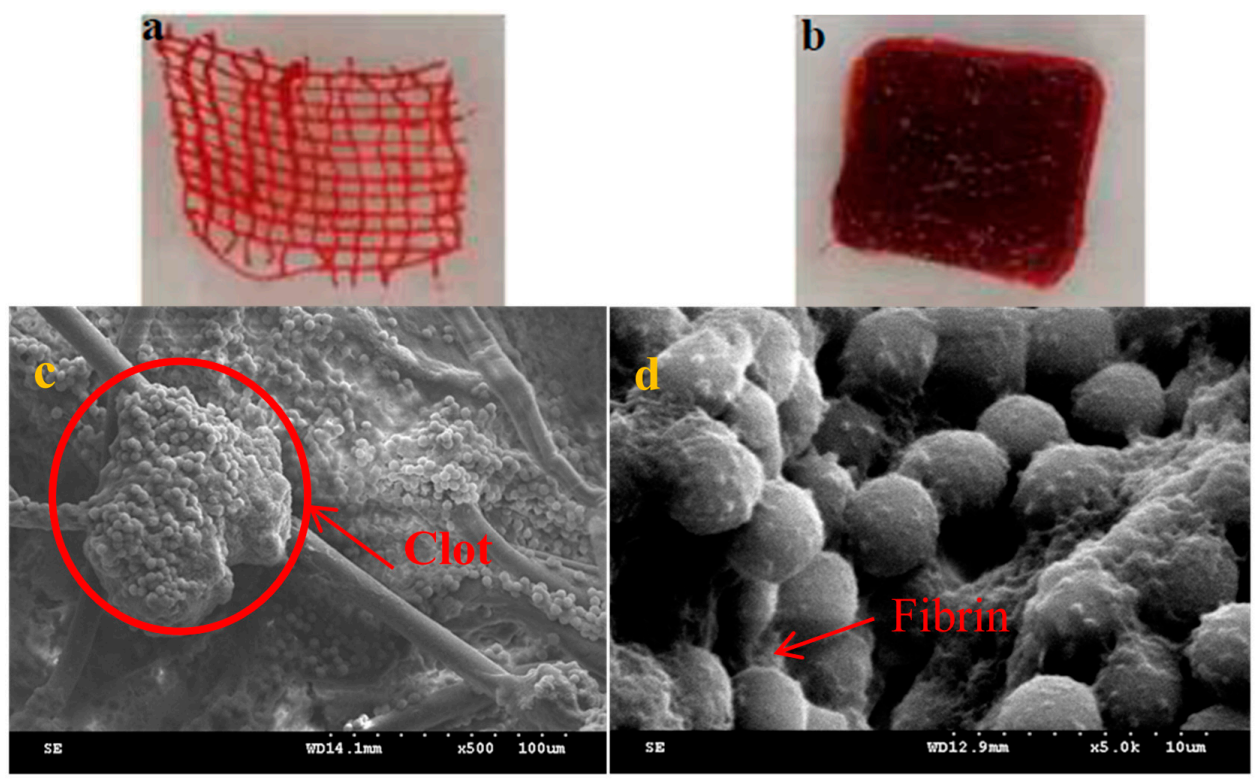

Figure 7. (a) Cotton cloth after blood absorption; (b) TCP nonwoven after blood absorption. SEM observation of TCP nonwoven after blood absorption (c: $500 \times$; d: $5000 \times$ ).

\subsection{Hemostatic Performance of Nonwoven Wound Dressing}

Figure 8 shows the PT and APTT of plasma and TCP nonwoven. Plasma was directly separated from the blood. Blood is originally a fluid, flowing along the horizontal test tube (Figure 8a). After activation, the agglutination reaction occurred, resulting in blood coagulation (Figure 8b). To prolong PT and APTT, heparin was added into plasma. Figure 8 displays that the clotting times of plasma in PT and APTT were 14.85 and $52.3 \mathrm{~s}$, respectively, and those with antibacterial agent (resultant wound dressing) were 14.34 (PT) and $50.94 \mathrm{~s}$ (APTT). Therefore, the PT and APTT of wound dressing decreased to $96.6 \%$ and $97.4 \%$, compared with those of plasma. The shortened time was due to platelets in plasma, which came into contact with chitosan in the antibacterial agent to generate an activated reaction, accompanied with extended and deformed pseudopodia, activated integrin compounds, calcium ion signal starting with platelet adherence, and accelerated combination fibrin monomer [47]. However, the PT and APTT of the resulting samples surpassed that of the control group (plasma) within less than $3 \mathrm{~s}$, demonstrating that wound dressing decreased the clotting time in PT and APTT insignificantly [48].
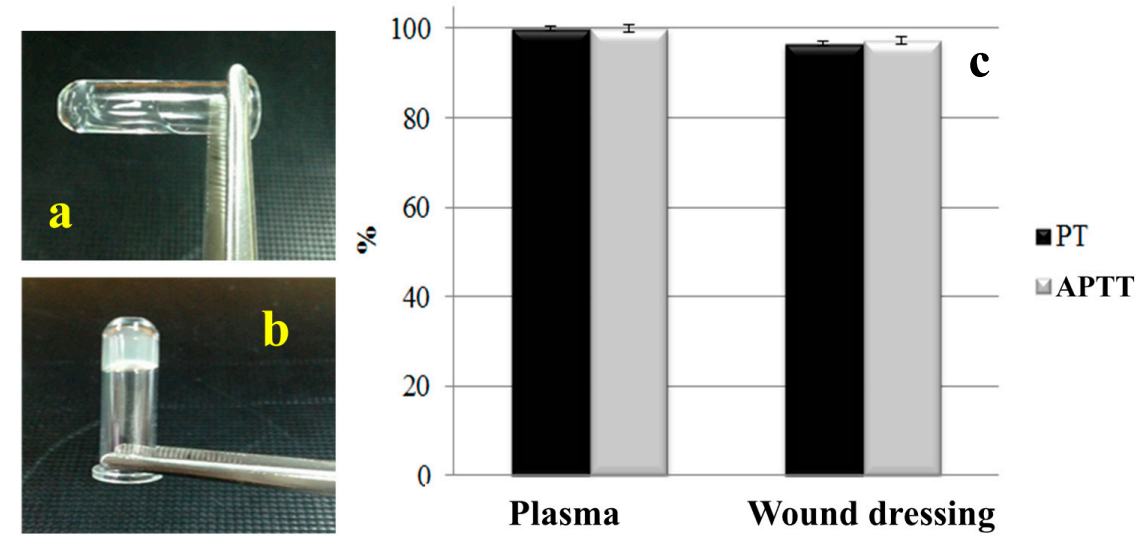

Figure 8. (a) Plasma; (b) its agglutination reaction and (c) prothrombin time (PT) and activated partial thromboplastin time (APTT) of wound dressing. 
Figure 9 shows the hemostasis time of rat femoral artery injury with various hemostatic materials. The hemostasis time of cotton cloth was $380 \mathrm{~s}$, and that of TCP nonwoven was shortened to $180 \mathrm{~s}$, a $52.6 \%$ decrease. The significant reduction in the hemostasis time for TCP nonwoven occurred because the TCP nonwoven, with a highly absorbent character, absorbed a large amount of blood quickly and facilitated the platelet agglutination reaction on the wound. The hemostasis time of wound dressing was $157 \mathrm{~s}$, which significantly decreased by $45 \mathrm{~s}$ compared with that of the TCP nonwoven base $\left({ }^{*} p<0.05\right)$. This finding indicates that the addition of antibacterial agent improved the hemostatic performance because the chitosan carrying positive ions triggered agglutination of erythrocytes and blood platelets, and plasma proteins were absorbed on the surface of the wound dressing upon contact with blood [36]. Nanosilver addition may reduce the bleeding amount and shorten the bleeding time, thereby demonstrating a hemostasis effect [35]. One-way ANOVA results indicated that the hemostasis time of wound dressing was also significantly shortened by $220 \mathrm{~s}$ compared with that of cotton cloth $\left({ }^{* *} p<0.01\right)$.

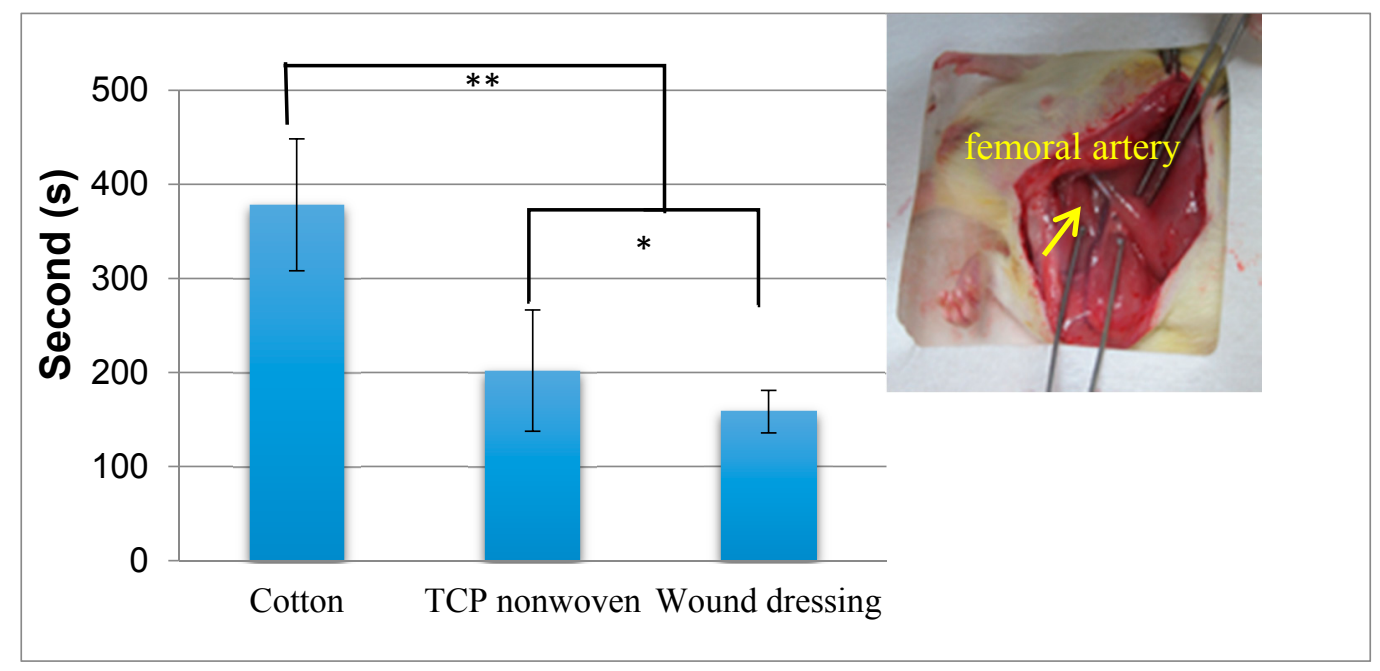

Figure 9. Comparisons of the hemostasis time of rat femoral artery injury by using cotton cloth (cotton), TCP nonwoven (TCP), and resultant wound dressing. ${ }^{* *} p<0.01 ;{ }^{*} p<0.05$.

\section{Conclusions}

In this work, we successfully fabricated a highly absorbent antibacterial hemostatic wound dressing composed of TCP nonwoven and then impregnated with chitosan/nanosilver antibacterial agent. The effects of nonwoven processing parameters on the vertical wicking property and the water and blood absorption of the TCP nonwoven were evaluated. Results showed that the vertical wicking height significantly increased with the Tencel ${ }^{\circledR}$ fiber content, punching density, and basis weight. Evidently, the water absorption ratio was correlated with the Tencel ${ }^{\circledR}$ fiber content and areal (basis) weight. Besides, the tensile strength of the TCP nonwoven increased significantly in relation to the Tencel ${ }^{\circledR}$ fiber content. The resulting nonwoven dressing base presented a tensile stress of 1.9-2.5 MPa and burst strength of 116-135 N, which could reach the mechanical levels of the wound dressing application. The TCP nonwoven showed very significant improvement in blood absorption compared with cotton cloth. Scaning electron microscopy (SEM) observations revealed that erythrocytes were in contact with nonwoven fibers, but they were successfully entrapped in the fibrin network and attached on the surface of nonwoven fibers. The PT and APTT time and hemostatic time in the rat femoral artery model of the wound dressing were further explored. Overall, the results indicated that the clotting time of wound dressing in PT and APTT array decreased to 14.34 and 50.94 s, respectively. Remarkably, the addition of antibacterial agent shortened the hemostatic time by $45 \mathrm{~s}$. These findings showed that 
the wound dressing in this study is a viable option for hemostatic wound dressing, especially in severe bleeding injuries.

Acknowledgments: This work was supported by National Science Foundation of China under Grant No. 51503145 and Ministry of Science and Technology of Taiwan under Grant No. NSC 102-2622-E-035-002-CC2. Jia-Horng Lin and Yueh-Sheng Chen contributed equally to this work.

Author Contributions: In this study, the concepts and designs for the experiment, the required materials, as well as the processing and assessment instruments were supervised by Jia-Horng Lin and Ching-Wen Lou. Experiment and data analysis were conducted by An-Pang Chen. Text composition and results analysis were performed by Ting-Ting Li. Hemostasis experimental result was examined by Tsing-Fen Ho, Mong-Chuan Lee and Yueh-Sheng Chen.

Conflicts of Interest: The authors declare no conflict of interest.

\section{References}

1. Murakami, Y.; Yokoyama, M.; Nishida, H.; Tomizawa, Y.; Kurosawa, H. A simple hemostasis model for the quantitative evaluation of hydrogel-based local hemostatic biomaterials on tissue surface. Colloid Surf. B 2008, 65, 186-189. [CrossRef] [PubMed]

2. Xu, H.; Ma, L.; Shi, H.; Gao, C.; Han, C. Chitosan-hyaluronic acid hybrid film as a novel wound dressing: In vitro and in vivo studies. Polym. Adv. Technol. 2007, 18, 869-875. [CrossRef]

3. Hattori, H.; Amano, Y.; Nogami, Y.; Takase, B.; Ishihara, M. Hemostasis for severe hemorrhage with photocrosslinkable chitosan hydrogel and calcium alginate. Ann. Biomed. Eng. 2010, 38, 3724-3732. [CrossRef] [PubMed]

4. Arafat, M.T.; Tronci, G.; Yin, J.; Wood, D.J.; Russell, S.J. Biomimetic wet-stable fibres via wet spinning and diacid-based crosslinking of collagen triple helices. Polymer 2015, 77, 102-112. [CrossRef]

5. Tronci, G.; Grant, C.A.; Thomson, N.H.; Russell, S.J.; Wood, D.J. Multi-scale Mechanical Characterization of Highly Swollen Photo-activated Collagen Hydrogels. J. R. Soc. Interface 2015, 12, 20141079. [CrossRef] [PubMed]

6. Tronci, G.; Doyle, A.; Russell, S.J.; Wood, D.J. Structure-property-function relationships in triple-helical collagen hydrogels. Mater. Res. Soc. Symp. Proc. 2013, 1498, 145-150. [CrossRef]

7. Taylor, J. Tencel—A unique cellulosic fibre. J. Soc. Dyers Colour. 1998, 114, 191-193. [CrossRef]

8. Schuster, K.C.; Suchomel, F.; Männer, J.; Abu-Rous, M.; Firgo, H. Functional and comfort properties of textiles from Tencel ${ }^{\circledR}$ Fibres resulting from the fibres' water-absorbing nanostructure: A review. Macromol. Symp. 2006, 244, 149-165. [CrossRef]

9. Saglam, A.; Bektas, S.; Patir, S.; Genç, Ö.; Denizli, A. Novel metal complexing ligand: Thiazolidine carrying poly(hydroxyethylmethacrylate) microbeads for removal of Cadmium(II) and Lead(II) ions from aqueous solutions. React. Funct. Polym. 2001, 47, 185-192. [CrossRef]

10. Jones, V.J. The use of gauze: Will it ever change? Int. Wound J. 2006, 3, 79-88. [CrossRef] [PubMed]

11. Levine, N.S.; Lindberg, R.A.; Salisbury, R.E.; Mason, A.D.; Pruitt, B.A. Comparison of coarse mesh gauze with biologic dressings on granulating wounds. Am. J. Surg. 1976, 13, 727-729. [CrossRef]

12. Townsend, C.M., Jr; Beauchamp, R.D.; Evers, B.M.; Mattox, K.L. Sabiston Textbook of Surgery; Elsevier Health Sciences: Philadelphia, PA, USA, 2012.

13. Malmsjö, M.; Ingemansson, R.; Martin, R.; Huddleston, E. Negative-pressure wound therapy using gauze or open-cell polyurethane foam: Similar early effects on pressure transduction and tissue contraction in an experimental porcine wound model. Wound Repair Regen. 2009, 17, 200-205. [CrossRef] [PubMed]

14. McGuckin, M.; Goldman, R.; Bolton, L.; Salcido, R. The clinical relevance of microbiology in acute and chronic wounds. Adv. Skin Wound Care 2003, 16, 12-23. [CrossRef] [PubMed]

15. Nathan, C. Points of control in inflammation. Nature 2002, 420, 846-852. [CrossRef] [PubMed]

16. Pusateri, A.E.; McCarthy, S.J.; Gregory, K.W.; Harris, R.A.; Cardenas, L.; McManus, A.T.; Goodwin, C.W., Jr. Effect of a chitosan-based hemostatic dressing on blood loss and survival in a model of severe venous hemorrhage and hepatic injury in swine. J. Trauma Acute Care 2003, 54, 177-182. [CrossRef]

17. Rao, S.B.; Sharma, C.P. Use of chitosan as a biomaterial: Studies on its safety and hemostatic potential. J. Biomed. Mater. Res. 1997, 34, 21-28. [CrossRef] 
18. Rajakannu, S.; Shankar, S.; Perumal, S.; Subramanian, S.; Dhakshinamoorthy, G.P. Biosynthesis of Silver Nanoparticles using Garcinia mangostana Fruit Extract and their Antibacterial, Antioxidant Activity. Int. J. Curr. Microbiol. Appl. Sci. 2015, 4, 944-952.

19. Mollick, M.M.R.; Rana, D.; Dash, S.K.; Chattopadhyay, S.; Bhowmick, B.; Maity, D.; Mondal, D.; Pattanayak, S.; Roy, S.; Chakraborty, M.; et al. Studies on green synthesized silver nanoparticles using Abelmoschus esculentus (L.) pulp extract having anticancer (in vitro) and antimicrobial applications. Arab. J. Chem. 2015. [CrossRef]

20. Dinesh, D.; Murugan, K.; Madhiyazhagan, P.; Panneerselvam, C.; Kumar, P.M.; Nicoletti, M.; Jiang, W.; Suresh, U. Mosquitocidal and antibacterial activity of green-synthesized silver nanoparticles from Aloe vera extracts: Towards an effective tool against the malaria vector Anopheles stephensi? Parasitol. Res. 2015, 114, 1519-1529. [CrossRef] [PubMed]

21. Logeswari, P.; Silambarasan, S.; Abraham, J. Synthesis of silver nanoparticles using plants extract and analysis of their antimicrobial property. J. Saudi Chem. Soc. 2015, 19, 311-317. [CrossRef]

22. Le Ouay, B.; Stellacci, F. Antibacterial activity of silver nanoparticles: A surface science insight. Nano Today 2015, 10, 339-354. [CrossRef]

23. Guzman, M.; Dille, J.; Godet, S. Synthesis and antibacterial activity of silver nanoparticles against gram-positive and gram-negative bacteria. Nanomed. Nanotechnol. Biol. Med. 2012, 8, 37-45. [CrossRef] [PubMed]

24. Krishnaraj, C.; Jagan, E.G.; Rajasekar, S.; Selvakumar, P.; Kalaichelvan, P.T.; Mohan, N. Synthesis of silver nanoparticles using Acalypha indica leaf extracts and its antibacterial activity against water borne pathogens. Colloids Surf. B Biointerfaces 2010, 76, 50-56. [CrossRef] [PubMed]

25. Sharma, V.K.; Yngard, R.A.; Lin, Y. Silver nanoparticles: Green synthesis and their antimicrobial activities. Adv. Colloid Interface 2009, 145, 83-96. [CrossRef] [PubMed]

26. Wei, D.; Sun, W.; Qian, W.; Ye, Y.; Ma, X. The synthesis of chitosan-based silver nanoparticles and their antibacterial activity. Carbohydr. Res. 2009, 344, 2375-2382. [CrossRef] [PubMed]

27. Maneerung, T.; Tokura, S.; Rujiravanit, R. Impregnation of silver nanoparticles into bacterial cellulose for antimicrobial wound dressing. Carbohydr. Polym. 2008, 72, 43-51. [CrossRef]

28. Kim, J.S.; Kuk, E.; Yu, K.N.; Kim, J.H.; Park, S.J.; Lee, H.J.; Kim, S.H.; Park, Y.K.; Park, Y.H.; Hwang, C.Y.; et al. Antimicrobial effects of silver nanoparticles. Nanomed. Nanotechnol. Biol. Med. 2007, 3, 95-101. [CrossRef] [PubMed]

29. Shrivastava, S.; Bera, T.; Roy, A.; Singh, G.; Ramachandrarao, P.; Dash, D. Characterization of enhanced antibacterial effects of novel silver nanoparticles. Nanotechnology 2007, 18, 225103. [CrossRef]

30. Duran, N.; Marcato, P.D.; De Souza, G.I.H.; Alves, O.L.; Esposito, E. Antibacterial effect of silver nanoparticles produced by fungal process on textile fabrics and their effluent treatment. J. Biomed. Nanotechnol. 2007, 3, 203-208. [CrossRef]

31. Shahverdi, A.R.; Fakhimi, A.; Shahverdi, H.R.; Minaian, S. Synthesis and effect of silver nanoparticles on the antibacterial activity of different antibiotics against Staphylococcus aureus and Escherichia coli. Nanomed. Nanotechnol. Biol. Med. 2007, 3, 168-171. [CrossRef] [PubMed]

32. Panáček, A.; Kvitek, L.; Prucek, R.; Kolar, M.; Vecerova, R.; Pizurova, N.; Nevěčná, T.; Zboril, R. Silver colloid nanoparticles: Synthesis, characterization, and their antibacterial activity. J. Phys. Chem. B 2006, 110, 16248-16253. [CrossRef] [PubMed]

33. Baker, C.; Pradhan, A.; Pakstis, L.; Pochan, D.J.; Shah, S.I. Synthesis and antibacterial properties of silver nanoparticles. J. Nanosci. Nanotechnol. 2005, 5, 244-249. [CrossRef] [PubMed]

34. Morones, J.R.; Elechiguerra, J.L.; Camacho, A.; Holt, K.; Kouri, J.B.; Ramírez, J.T.; Yacaman, M.J. The bactericidal effect of silver nanoparticles. Nanotechnology 2005, 16, 2346-2353. [CrossRef] [PubMed]

35. Lin, J.H.; Chen, A.P.; Li, T.T.; Lin, M.C.; Lou, C.W. Antibacterial behavior and physical properties of silver nanoparticle-doped ecofriendly nonwoven fabrics. Cellulose 2014, 21, 1957-1964. [CrossRef]

36. Lou, C.W.; Chen, A.P.; Lic, T.T.; Lin, J.H. Antimicrobial activity of UV-induced chitosan capped silver nanoparticles. Mater. Lett. 2014, 128, 248-252. [CrossRef]

37. Mao, N.; Russell, S.J. Anisotropic liquid absorption in homogeneous two-dimensional nonwoven structures. J. Appl. Phys. 2003, 94, 4135-4138. [CrossRef]

38. Çil, M.G.; Nergis, U.B.; Candan, C. An experimental study of some comfort-related properties of cotton-acrylic knitted fabrics. Text. Res. J. 2009, 79, 917-923. [CrossRef] 
39. Debnath, S.; Madhusoothanan, M. Water absorbency of jute-polypropylene blended needle-punched nonwoven. J. Ind. Text. 2010, 39, 215-231. [CrossRef]

40. Parikh, D.V.; Thibodeaux, D.P.; Sachinvala, N.D.; Moreau, J.P.; Robert, K.Q.; Sawhney, A.P.S.; Goynes, W.R. Effect of cotton fiber mercerization on the absorption properties of cotton nonwovens. AATCC Rev. 2006, $6,38-43$.

41. Duru, S.C.; Candan, C. Effect of repeated laundering on wicking and drying properties of fabrics of seamless garments. Text. Res. J. 2013, 83, 591-605. [CrossRef]

42. Laughlin, R.; Davies, J. Some aspects of capillary absorption in fibrous textile wicking. Text. Res. J. 1961, 31, 904-910. [CrossRef]

43. Lin, J.H.; Chen, A.P.; Lin, J.Y.; Lin, T.A.; Lou, C.W. Manufacturing technique and mechanical properties of environment-protective composite nonwoven fabrics. Adv. Mater. Res. 2011, 287, 2673-2676. [CrossRef]

44. Das, A.; Raghav, R.J. Bursting behavior of spunbonded nonwoven fabrics: Part I-Effect of various parameters. Indian J. Fibre Text. 2010, 35, 258-263.

45. Terrill, P.; Sussman, G.; Bailey, M. Absorption of blood by moist wound healing dressings. Prim. Intent. 2003, 11, 7-17.

46. Pretorius, E.; Bester, J.; Vermeulen, N.; Lipinski, B.; Gericke, G.S.; Kell, D.B. Profound morphological changes in the erythrocytes and fibrin networks of patients with hemochromatosis or with hyperferritinemia, and their normalization by iron chelators and other agents. PLoS ONE 2014, 9, e85271. [CrossRef] [PubMed]

47. Warren, B.A. The ultrastructure of platelet pseudopodia and the adhesion of homologous platelets to tumour cells. Br. J. Exp. Pathol. 1970, 51, 570-580. [PubMed]

48. Liao, C.C.; Hsieh, P.C.; Lin, T.K.; Lin, C.L.; Lo, Y.L.; Lee, S.C. Surgical treatment of spontaneous spinal epidural hematoma: A 5-year experience: Clinical article. J. Neurosurg. 2009, 11, 480-486. [CrossRef] [PubMed]

(C) 2016 by the authors; licensee MDPI, Basel, Switzerland. This article is an open access article distributed under the terms and conditions of the Creative Commons Attribution (CC-BY) license (http://creativecommons.org/licenses/by/4.0/). 